Geografia e Ordenamento do Território, Revista Electrónica

Centro de Estudos de Geografia e Ordenamento do Território

http://cegot.org

ISSN :2182-1267

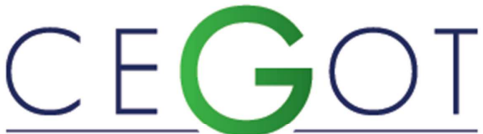

Centro de Estudos de Geografia e Ordenamento do Território
MORCUENDE, ALEJANDRO

Observatori del Comerç de la Universitat de Barcelona / Grup de Recerca Consolidat d'Anàlisi

Territorial i Desenvolupament Regional - ANTERRIT

/ Universitat de Barcelona

Gran Via de Les Corts Catalanes, 585, 08007 Barcelona,

Espanha

Alejandro.morcuende@gmail.com

\title{
Emigración y juventud: cómo los jóvenes en Cataluña escapan a un modelo productivo en crisis
}

\author{
Emigração e juventude: como os jovens catalães escapam de um modelo \\ produtivo em crise \\ Emigration and youth: how catalan young people escape from an \\ unsuccessful production model
}

Referência: Morcuende, Alejandro (2015). Emigración y juventud: cómo los jóvenes en Cataluña escapan a un modelo productivo en crisis. Revista de Geografia e Ordenamento do Território (GOT), n.o 8 (dezembro). Centro de Estudos de Geografia e Ordenamento do Território, p. 103-131, dx.doi.org/10.17127/got/2015.8.006

\section{RESUMEN}

Este artículo tiene como objetivos principales la caracterización de la situación de la juventud catalana en las últimas décadas, el estudio del proceso migratorio de la juventud cualificada enmarcada dentro de las actuales dinámicas económicas y sociales a nivel europeo, así como la búsqueda de elementos explicativos de las causas de dicha emigración. Es harto conocido que las generaciones más jóvenes son hoy las más formadas de las últimas décadas; conocido es también, no sin muchas incógnitas alrededor de sus causas y sus consecuencias, que la emigración juvenil es ya un hecho como intento de búsqueda de oportunidades negadas en las ciudades de origen. La actual crisis económica, y las políticas de respuesta, han venido deteriorando las condiciones materiales de las poblaciones europeas, y en especial de muchos jóvenes, que ven negados derechos básicos para una emancipación plena. Se señala en esta comunicación esta emancipación negada, esos derechos vulnerados, como la principal vía de explicación de las actuales salidas de jóvenes catalanes al extranjero.

Palabras clave: emigración juvenil, emancipación, paro juvenil, precariedad laboral, acceso a la vivienda 


\section{RESUMO}

Os principais objetivos são caracterizar a situação dos jovens da Catalunha nas últimas décadas, e promover o estudo da migração de jovens qualificados no contexto dos parâmetros económicos e sociais em curso na dinâmica a nível europeu, bem como avaliar as causas desta emigração. É bem sabido que as gerações mais novas são hoje as melhor formadas nas últimas décadas; Sabe-se também, ainda que com muitas dúvidas sobre suas causas e consequências, que a migração dos jovens é um facto e uma tentativa de encontrar oportunidades negadas nas cidades de origem. A crise económica e as políticas adotadas levaram à deterioração das condições materiais das populações europeias, especialmente dos jovens aos quais são negados direitos básicos para a plena emancipação. Esta emancipação negada é exposta na presente comunicação, considerando os direitos violados como a principal forma de explicação da atual saída de jovens catalães para o exterior.

Palavras-chave: migração da juventude, emancipação, desemprego juvenil, precariedade, acesso à habitação

\section{ABSTRACT}

This article, that belongs to a more wide research of final Master report, takes as principal aims the characterization of the situation of the catalan youth in the last decades, the study of the migratory process of the qualified youth framed inside the current european economic and social dynamics, as well as the search of explanation elements of the reasons of this emigration. Is already well known that the current youngest generations are the most qualified of last decades; is well known also, not without many doubts about his reasons and his consequences, that this young emigration process is already a fact as an attempt to unsuccessfully search of some job opportunity in their own cities. The current economic crisis, and the policies of response, they have come spoiling the material conditions of the European populations, and especially of many young people, who see denied their basic rights for a full emancipation. This useless emancipation is considered as the principal way of explanation of the current exit of catalan young people abroad.

Keywords: youth emigration, emancipation, youth unemployment, job insecurity, housing

\section{Introducción}

Tratando este trabajo de los flujos migratorios y del reciente fenómeno de la emigración juvenil en Cataluña no podía empezar de otra manera que recordando a Antonio López y López (Cantabria, 1817-1883) ${ }^{1}$, primer Marqués de Comillas y uno de los más ilustres emigrantes de la historia moderna de las migraciones hispanas. Joven emigrante, Antonio López fue de aquellos

\footnotetext{
${ }^{1}$ Para saber más sobre Antonio López y López y el marquesado de Comillas consultar: RODRIGO,M; “Antonio López y López, 1817-1883: primer Marqués de Comillas: un empresario y sus empresas", Fundación Empresa Pública 1996
} 
que "hicieron las Américas", hoy sería considerado un emprendedor, marchó joven e hijo de humilde pescadera y retornó banquero e inversor en el tráfico de esclavos.

Con la esclavitud prácticamente abolida, bancos con claras necesidades de recapitalización y una economía de oligopolios "hacer las Américas" es hoy harto complicado. La juventud catalana, caracterizada por el paro, la precariedad y la inestabilidad laboral, empieza a no tener más esperanza que la de prosperar humildemente lejos de sus ciudades de origen. Y es que así como en el siglo XIX los indianos hicieran las Américas, los jóvenes catalanes se disponen para el necesario "rehacer de las Europas".

Son muchas las evidencias que apuntan a que el fenómeno objeto de estudio, la emigración internacional de los jóvenes catalanes, experimenta incrementos claros en el número de salidas a raíz de la crisis que se inicia en el año 2008 en España ${ }^{2}$, cuya consecuencia principal es el agravamiento de la situación en la que se encuentran los jóvenes a partir de la crisis global de 2007. Dicha crisis ha ocupado la vida económica, política y social en todos los países afectados, especialmente en la periferia sur europea, donde la situación se ha ido agravando dramáticamente. De igual forma, y como consecuencia de ello, la vida académica y sus trabajos también han girado entorno a las consecuencias de la crisis en cualquiera de los ámbitos de estudio.

Las Ciencias Sociales han intentado desde diferentes disciplinas, metodologías y enfoques dar respuesta y entender la crisis económica de $2007^{3}$; algo que se antoja improbable de totalizar, ya que la crisis presenta numerosas caras, demasiadas causas y múltiples consecuencias. El fin de una época y el inicio de otra son cuestiones poco discutidas, así pues habrá que seguir indagando qué situaciones de todas las que vivimos son consecuencia o no de este "cambio de época".

Realizadas estas dos afirmaciones, que la emigración juvenil se dispara con la crisis y que ésta aún deja interrogantes en su explicación, puede tomarse como primera justificación del objeto de estudio lo que sigue a continuación. El análisis de la emigración juvenil como consecuencia de la situación de los jóvenes en las ciudades de origen a causa de las políticas de austeridad supone estudiar un lado más del fin de época; tarea esta última, que nadie discute resulta imprescindible para realizar los cambios pertinentes en la ordenación de la vida en las sociedades contemporáneas.

Lo reciente del fenómeno, elemento nada cuestionable, y lo estadísticamente poco significativo de los casos, hace de la emigración de los jóvenes catalanes algo poco, o nada, estudiado. Como

\footnotetext{
${ }^{2}$ EI PIB del Estado Español no decreció hasta el último trimestre del año 2008. Fuente: Instituto Nacional de Estadística (INE).

${ }^{3}$ Como ejemplos se pueden citar los trabajos de los economistas Thomas Piketty y Angus Deaton en una dinámica global, del historiador catalán Xavier Domènech y su estudio de los movimientos sociales a raíz de la crisis económica en España, y del constitucionalista Gerardo Pisarello y su trabajo sobre la posibilidad de un proceso constituyente en España tras la crisis política y de legitimidad de las instituciones españolas tras la crisis de 2008.
} 
consecuencia de todo ello resulta especialmente dificultoso adentrarse en la exploración del tema, especialmente a causa de la falta de datos, de información, de base teórica, entre otros elementos imprescindibles para establecer conclusiones científicamente robustas.

El fenómeno de la emigración juvenil, presumiblemente, y de seguir una tendencia como la que se observa en los datos de los que se dispone, puede llegar a tener relevantes consecuencias sobre la región emisora, en este caso Cataluña. El estudio del flujo de jóvenes catalanes al exterior debe ser analizado con el objetivo de dilucidar cuáles serán las consecuencias sobre nuestra estructura social -estructura económica y política, mercado de trabajo y condiciones sociales-, determinando así el alcance de los mismos. Asimismo, y aunque la dificultad en el tratamiento de la cuestión es evidente, se deben realizar investigaciones en torno de la emigración juvenil para así ir encontrando pistas y evidencias que conduzcan a nuevas conclusiones.

El estudio de la emigración ocupa numerosas tesis, textos e investigaciones. Del mismo modo los flujos migratorios referidos al Estado español han sido objeto de estudio y análisis, especialmente tras los fenómenos dados a partir de los últimos años del siglo XX y los primeros años de la actual centuria. La primera década del siglo XXI ha dejado, en el ámbito de las migraciones, dos fenómenos relevantes a los que se les ha otorgado diferente importancia científica y política.

El primero de estos fenómenos, que ha sido tratado desde múltiples disciplinas, es el exponencial aumento de población extranjera llegada al Estado español en los años finales de la década de los noventa e inicio del siglo. La cuestión de la inmigración extranjera ha sido objeto de estudio por parte de la sociología, la economía, la demografía, la geografía, la antropología y la ciencia política principalmente, desde diferentes enfoques y metodologías. Sin duda la gran cantidad de información alrededor de la cuestión ha dejado un mejor comprensión científica del fenómeno, que sin embargo no se ha traducido en una gestión política y administrativa adecuada.

Es a partir de la crisis del petróleo de 1973 y con el régimen franquista en sus años de agonía España empezó a cambiar su tendencia emisora de emigrantes a la de receptora de personas inmigradas. Con la restitución de la democracia y la entrada en el euro años más tarde, todas aquellas personas que por diferentes motivos emigraron en las décadas anteriores a los años 70 iniciaron su retorno a España. Asimismo con el inicio de cierta expansión económica y el desarrollo del Estado del Bienestar, así como un modelo productivo basado en la construcción y demanda de mano de obra no cualificada, se inició a partir de los años 90 una llegada importante de inmigración extranjera hasta situarse en el 2012 en el 12,1\% del total de la población en España ${ }^{4}$.

Presumiblemente el segundo de los fenómenos que ha dejado las primeras décadas del siglo $X X I$, cogiendo de alguna manera el testigo de la inmigración extranjera como uno de los fenómenos migratorios principales, será el de la emigración juvenil. Cabe decir que esto

\footnotetext{
${ }^{4}$ Fuente: Instituto Nacional de Estadística (INE)
} 
constituye una de las líneas principales de justificación del trabajo que será desarrollada en sucesivos apartados.

El fenómeno migratorio de la juventud tanto en Cataluña, como en el resto del Estado, ha ocupado y sigue ocupando páginas de diarios y minutos en programas y noticias en televisión. La emigración juvenil podría parecer pues una exageración, un fenómeno periodístico sin base significativa para su estudio y análisis. Sin duda en los últimos decenios la movilidad de jóvenes, especialmente dentro del marco europeo, ha venido aumentando. No obstante el contexto de las últimas décadas quedó atrás; desde 2008 las condiciones materiales de millones de familias en todo el Estado español han cambiado radicalmente, en su inmensa mayoría para menguarse y deteriorarse. Es probable que el mismo fenómeno en tiempos de bonanza económica encuentre diferentes causas, y aún más diferentes consecuencias, que bajo el contexto económico, político y de emergencia social que hoy domina el Estado español.

La situación de la juventud catalana que será desgranada en siguientes apartados, presenta un empeoramiento de sus condiciones de vida. El paro, la cada vez mayor exclusión de la educación superior, y la imposibilidad de acceder a una vivienda digna resumen la caracterización de los jóvenes hoy en Cataluña. Partir de esta caracterización, y el estudio de los elementos explicativos de su porqué, llevan a realizar el trabajo partiendo de que la movilidad ha dado paso a la emigración, y que a pesar de no ser hoy un fenómeno estadísticamente significativo, si son social, política y económicamente significativas sus causas y sus consecuencias. Cabe además recordar que nunca la ciencia debe guiarse por consideraciones realizadas ex- ante, ni avanzar en conocimientos de acuerdo a intereses o razones privadas.

Se sostiene a lo largo del trabajo que la principal causa de la emigración juvenil es la emancipación negada, es decir, la imposibilidad de generar un proyecto de vida propio en la ciudad de origen o residencia. Que la emancipación sea negada implica política de negación, instituciones y agentes que nieguen. Efectivamente que la juventud hoy en España no pueda acceder a un empleo estable ni tenga capacidad para adquirir una vivienda digna encuentra explicación en un modelo productivo en crisis y un régimen político socialmente cuestionado que ha venido legislando a favor de la temporalidad y la precariedad juvenil.

Se hace necesario pues en la introducción previa al abordaje de la cuestión de la emigración juvenil realizar un repaso a los flujos migratorios contemporáneos en el Estado español, que permita dibujar la realidad histórica en la que se debe enmarcar el estudio de los actuales flujos de emigración juvenil. Por último se realizará una primera aproximación al fenómeno de la emigración juvenil con su correspondiente estado de la cuestión como materia científica.

\section{Las migraciones contemporáneas en el Estado español ${ }^{5}$}

Los flujos migratorios en España han variado en intensidad y dirección a lo largo de toda la historia, siendo estos flujos los que han determinado la localización y la redistribución de la

\footnotetext{
${ }^{5}$ ROMERO VAlIENTE, JM; Capítulo “5. Migraciones” en "Tendencias demográficas durante el siglo XX en España", INE 2003
} 
población a lo largo del territorio. Las migraciones contemporáneas, las comprendidas entre el siglo XIX y la actualidad, constituyen los movimientos más importantes que han moldeado económica, política y socialmente las ciudades más importantes del Estado.

En lo que se refiere a las migraciones interiores cabe situar su arranque y toma de relevancia a partir del siglo XIX. Entre las décadas finales del XIX y 1975 se dan las migraciones interiores que tienen como origen el mundo rural y como claro destino las zonas urbanas, contabilizándose un desplazamiento de más de 15 millones de personas en ese margen temporal. Con el proceso de industrialización se inició el proceso de migración interior en España, así como con el desarrollo de los transportes. Durante este proceso, al que cabe sumarle el deterioro de la vida rural con sucesivas crisis agrícolas, las zonas receptoras son Madrid, Barcelona y el País Vasco. Las dos últimas se ven reforzadas por sus incipientes industrias, textil y siderúrgica respectivamente, y Madrid refuerza su papel de capital administrativa y centro de negocios, con las sedes de bancos principalmente.

A partir de la década de 1920, con el impulso de obras públicas de gran envergadura que coincidirán con la Exposición Universal en Barcelona y la Exposición Iberoamericana de Sevilla, ambas de 1929, harán de la capital hispalense un foco receptor de personas. Las dos Castillas, las provincias levantinas, Murcia y el resto de provincias andaluzas, Galicia, Cantabria y Asturias constituyen las zonas de emisión de emigrantes durante la década.

Con la depresión económica mundial de los años 30 y los grandes cambios políticos en España se produce un estancamiento de las migraciones interiores. La situación económica empeorará con las consecuencias de la Guerra Civil (1936-1939), hecho que contribuirá también al estancamiento de la migración en España, al ser más probable el sustento material en el campo que en las incipientes urbes españolas. No obstante la posguerra y la dictadura franquista dejarán desplazamientos masivos de población por motivos políticos. De nuevo Madrid, Barcelona, el País Vasco y Valencia serán las principales zonas de recepción de emigrantes.

La situación cambia cuando durante las décadas de 1950 y 1960 el automóvil privado se empieza a generalizar, lo que unido al desarrollismo propio de los años 60 dará una importancia cada vez mayor en el modelo productivo al sector servicios, provocará un aumento de las migraciones interiores. Estos flujos presentarán nuevas características, entre ellas, la generalización de los movimientos en todo el territorio, siendo la mayoría de ciudades emisoras o receptoras, ya no se circunscribe el fenómeno a un puñado de zonas. Estos flujos serán de largo recorrido, superando el movimiento provincial y situando a todas las capitales de provincia como receptoras de emigrantes.

Unido a lo anterior estas nuevas migraciones interiores darán paso al fenómeno metropolitano, haciendo crecer los municipios circundantes a las principales ciudades de España. Todas estas características, nuevos procesos al fin y al cabo, provocarán una reducción acentuada del éxodo rural.

Las dinámicas de los flujos migratorios interiores cambiarán radicalmente a partir de 1975, a causa de los cambios políticos y económicos que se dan en España, así como la crisis económica 
mundial que tuvo lugar durante los años setenta y ochenta. Esta nueva etapa se caracterizará por unos flujos pluridireccionales donde los saldos extremos quedarás suavizados, las migraciones se producirán ahora de acuerdo a nuevos valores post-materiales como el entorno o la calidad de vida en detrimento de la exclusividad de las razones laborales. El progreso en las comunicaciones y los transportes dará paso a movimientos temporales y de más corta distancia, principalmente intraprovinciales. Por último la migración a las grandes ciudades se detendrá y las ciudades medias iniciarán su incremento de población.

A pesar de que a partir de 1975 se producirá un descenso de las migraciones, a partir de la década de los noventa se consolidarán todos los cambios en los flujos migratorios interiores que se han detallado con anterioridad. No obstante a final del siglo se producirá un incremento importante de las migraciones por motivación residencial, dándose los movimientos interiores más importantes del siglo. Sin duda, el final de siglo deja constatado que los flujos migratorios interiores guardan estrecha relación con la situación económica del país, hecho que resulta relevante para el desarrollo del trabajo que se presenta.

Para finalizar el repaso a las migraciones contemporáneas en España se presenta la caracterización de las migraciones exteriores de finales del siglo XIX hasta la actualidad. Se parte de un elevado flujo migratorio hacia América entre las décadas finales del siglo XIX y las primeras del XX, a causa del ligero despegue económico de las colonias ultramarinas de América y un crecimiento demográfico en España que no se corresponde con el aprovechamiento suficiente de los recursos disponibles. Se estima que alrededor de 3 millones y medio de españoles partieron a América entre 1880 y 1930. Por otro lado la inmigración extranjera llegada a España por entonces se reduce a 76.000 personas, en su inmensa mayoría de nacionalidad francesa o portuguesa.

Con la crisis económica de 1929 se inicia un retorno de los emigrados anteriormente, de los que se calcula que volvieron algo más de la mitad. A esto cabe sumar los años de la Guerra Civil (1936-1939) que acusaron el descenso de la inmgración extranjera hasta su finalización en la que muchas personas se vieron forzadas al exilio, principalmente con destino al sur de América. Las política de inmigración impuestas por el régimen franquista y la situación vivida a raíz de la Segunda Guerra Mundial (1939-1945) provocan seguidamente al exilio de miles de españoles un nuevo descenso de los flujos migratorias hacia fuera de España.

Durante la década de 1950 y 1960 con el fin de la Guerra Mundial y el inicio de políticas desarrollistas y el Estado del Bienestar en la Europa Occidental, harán de estos países -Francia, Alemania y Suiza, principalmente- los nuevos polos de atracción de emigrantes españoles en detrimento de los países americanos.

A partir de 1973 con la crisis del petróleo y de 1975 con la Reforma Política que daba paso al Régimen Constitucional los flujos se invierten, y de nuevo se inicia un proceso de retorno. Tanto es así que en el último lustro de los setenta las entradas de inmigrantes superan a las salidas, hecho que se mantendrá hasta el inicio de la crisis de 2008 cuando hemos asistido a importantes cambios de dinámica. Es a partir de la década de los años 80 cuando se inicia cierta atenuación 
del retorno de españoles y empieza a incrementarse -a final de la década- la entrada de inmigración extranjera. Tanto es así que en 1988 se registraban en España alrededor de 14.000 personas extranjeras y en 2001 se pasa a más de 380.000. Si hasta el 2001 el origen de la inmigración extranjera era principalmente de otros países de la Unión Europea, a medida que nos adentrábamos en la primera década del siglo XXI llegaban a España personas de países de origen extracomunitarios.

Este será sin duda el fenómeno migratorio que más consecuencias políticas, económicas y sociales ha tenido para España, al representar un fenómeno de llegada de personas de orígenes muy diferentes y con comportamientos distintos, en un momento de expansión económica al que le ha seguido una fuerte recesión, tan inesperada como la llegada masiva de personas extranjeras.

\section{La emigración juvenil}

¿Emigración o movilidad? ¿Exilio u oportunidad? El debate entorno al fenómeno migratorio de los jóvenes españoles está servido. Las fuentes periodísticas que tratan el asunto desde ópticas diferentes son numerosas, así como las declaraciones de políticos, sindicatos o asociaciones juveniles en uno $u$ otro sentido sobre la marcha de miles de jóvenes fuera de su ciudad de origen en busca, principalmente, de un empleo. Sin embargo se requieren fuentes de robusto carácter científico para el trato académico de lo que seguro es un proceso de dramáticas causas y, aún más dramáticas, consecuencias.

La bibliografía que ha tratado la cuestión de la emigración en sentido amplio se puede clasificar en tres grandes conjuntos temáticos; cabe decir que las metodologías son transversales y no coinciden con la clasificación propia que se presenta. En primer lugar encontramos estudios de claro carácter sociológico que pretenden explicar la situación de los emigrantes españoles en toda su globalidad en un lugar concreto. Especial atención han tenido los casos de los emigrantes españoles a América fruto del exilio posterior a la Guerra Civil (1936-1939) o los procesos migratorios de finales del siglo XIX cuando aún se mantenían las colonias ultramarinas; ejemplo claro constituye "La Emigración española a América: siglos XIX y XX" de Yáñez Gallardo publicado en $1994^{6}$.

En segundo lugar encontramos los trabajos sectoriales que tratan algún aspecto concreto de la población emigrada. Así se ha publicado alrededor de las migraciones económicas o por razones laborales, entorno a la cuestión de la identidad y la lengua en las poblaciones emigradas, estudios de carácter jurídico, de corte cultural y desde una perspectiva de género. Por último encontramos aquellos trabajos que han tratado la emigración desde un punto de vista teórico o histórico, que relacionan conceptos como el desarrollo o la pobreza con la emigración u ofrecen perspectiva histórica a algún flujo de una población a otra concreta. Un estudio de carácter

\footnotetext{
${ }^{6}$ YAÑEZ GALLADO, C; “La Emigración española a América : siglos XIX y XX : dimensión y características cuantitativas" Archivo de Indianos 1994
} 
teórico entorno a la emigración y el desarrollo es el estudio editado por José Antonio Alonso "Emigración, pobreza y desarrollo" publicado en el año 2004 .

En esta breve revisión bibliográfica sobre la emigración es importante señalar la dificultad a la hora de encontrar trabajos entorno a la emigración y la juventud. Cabe mencionar regulares estudios entorno a la situación de la juventud que suelen publicar las secciones juveniles de las principales centrales sindicales, CCOO y UGT; en estos estudios se incluyen desde el año 2011 análisis sobre el fenómeno de la emigración juvenil. A esto se le debe sumar que a nivel teórico tampoco se trata a la juventud como un caso particular que merezca, como mínimo, una mención a las posibles características diferenciadas como flujo migratorio.

Como en todos los casos y fenómenos migratorios las poblaciones que comparten las mismas condiciones presentan diferentes comportamientos y conductas. En el caso de los jóvenes catalanes aunque la mayoría de ellos viven características similares de paro y precariedad, son varias las condiciones que deben presentar para que se de la emigración, es decir, se puede trazar un perfil muy concreto para los jóvenes catalanes emigrados, aspecto que se ha desarrollado en el análisis posterior a la realización de las entrevistas. Aunque la emigración de jóvenes ha aumentado en los últimos años, y aún y compartir una muy parecida situación social, no todos los jóvenes parten de unas mismas condiciones que faciliten la emigración ${ }^{8}$.

Por último se repasa la bibliografía referente a la emancipación juvenil, temática que ha sido ampliamente abordada por la academia. La amplia mayoría de los estudios entorno a la emancipación de los jóvenes trata de comparar y realizar series históricas de las pautas de emancipación, así como centrándose en estudios de edad de emancipación y vivienda. A destacar "Pasado y presente de las pautas de emancipación juvenil en España" ${ }^{9}$ de Pau Miret, sociológo del Centre d'Estudis Demogràfics, así como "La Vivienda como determinante de la emancipación juvenil" ${ }^{10}$ de Pedro Serrano.

Se define aquí la concepción entorno a "emancipación" con la que se trabajará a lo largo del desarrollo del trabajo. Se entiende por emancipación la capacidad de tener recursos materiales para no depender de nadie; concretándose por un lado en una independencia económica, y por otro en una independencia domiciliaria de los padres o tutores. Para ello es imprescindible el acceso a un empleo estable y digno, y la garantía del acceso a una vivienda, factor fundamental para la emancipación en todos los estudios realizados entorno a esta cuestión.

\footnotetext{
${ }^{7}$ ACOSTA, A[et al]; “Emigración, pobreza y desarrollo", Catarata 2004

${ }^{8}$ MASSEY, D, “"Theories on internacional migration: a review an appraisal"; Population and Development review, 1993 pag 431-466

9 MIRET, P, “Pasado y presente de las pautas de emancipación juvenil en España"; CCCB, Barcelona 1997

${ }^{10}$ SERRANO, P, “La Vivienda como determinante de la emancipación juvenil”; CCCB, Barcelona 1997
} 


\section{Objetivos, hipótesis y metodología}

Se exponen a continuación los objetivos y las hipótesis que van a guiar las líneas de investigación del trabajo, así como la metodología empleada en el mismo para la resolución de dichos objetivos e hipótesis. El planteamiento de los objetivos permite fijar las líneas a seguir a lo largo de todo el trabajo. Una simple enumeración de los objetivos sería insuficiente, por lo que se contextualiza y argumenta su razón de ser como objetivos principales del trabajo.

Definimos en primer lugar en este apartado el objeto de estudio del trabajo; jóvenes de 18 a 30 años nacidos en Cataluña y formados en los centros educativos -secundarios o superiores- de Cataluña que se encuentran residiendo fuera del Estado español. La justificación de la horquilla de edad se corresponde con una concepción de lo juvenil como etapa entre la adolescencia donde también incluimos el factor de la cualificación, en posesión como mínimo del Título de Bachillerato- y la edad adulta, caracterizada por cierta estabilidad económica y personal. No obstante la concepción general que se maneja a lo largo del artículo en relación a la juventud es, por un lado, concebir a la juventud como un grupo social que comparte unas condiciones materiales, y en segundo y más importante, una consideración de la juventud como la voluntad y capacidad de emprender proyectos propios de vida.

A pesar de que el objeto de estudio sean jóvenes catalanes en algunos de los apartados analíticos se debe tomar la perspectiva del Estado español, cuyas dinámicas políticas, económicas y sociales son indisociables de las de Cataluña.

El primero de los objetivos es pues determinar cual es la radiografía de la situación de la juventud hoy en Cataluña. Resulta imprescindible conocer a fondo al objeto de estudio, los jóvenes catalanes; cuántos son, cómo son, y por supuesto, cuáles son sus condiciones de vida. En la respuesta a estas preguntas encontraremos, de acuerdo a las hipótesis que guían este trabajo, numerosos indicadores que expliquen los porqués de la marcha de estos jóvenes a otros países que se sitúan en las condiciones de trabajo, y de vida al fin al cabo, en las que viven la inmensa mayoría de los jóvenes en Cataluña. Así, las tasas de paro, la edad media de emancipación, los tipos de contratos en los que se encuentran empleados, entre múltiples indicadores más, darán buena cuenta de la situación de nuestro objeto de estudio, además de ofrecer líneas a seguir en el que constituye el segundo de los objetivos principales del trabajo.

Determinar cuales son las causas de la emigración juvenil, las motivaciones de la juventud a la salida del país en busca de algo que presuponemos negado en la ciudad de origen; esto constituye el segundo objetivo del trabajo. Para ello se partirá del primer objetivo, la situación de la juventud en Cataluña, se dará explicación a esa situación, que la tiene, y se contextualizará el fenómeno en lo que ya es una de las crisis más importantes del capitalismo. Por otro lado se aportará nueva información construida a partir de entrevistas de respuesta breve, aunque de carácter cualitativo, a jóvenes catalanes que se encuentran residiendo en el extranjero. De esta información no se pretende establecer conclusiones generales, ni disponer de elementos 
explicativos; tan sólo se persigue el hallazgo de pistas, de indicios que refuercen las hipótesis planteadas y que irán guiando el trabajo.

Por último el tercero de los objetivos, que se antoja el más complejo, pretende realizar diferentes constataciones a partir de la revisión de las principales teorías de las migraciones contemporáneas. La revisión debe ayudar a establecer diferentes determinaciones que surgirán principalmente de la reflexión crítica de las aportaciones neoclásicas y funcionalistas, y de la validez de algunos elementos de ciertas aportaciones teóricas.

La falta de corpus teórico coherente, de la existencia de varias teorías explicativas de los fenómenos migratorios, complica el establecimiento de marcos teóricos predeterminados, para acogerse a una teoría u otra. Se persigue en el apartado donde se fija el marco teórico del trabajo enumerar las consideraciones teóricas en torno a las migraciones que forman el marco teórico con el que explicaremos la emigración de los jóvenes catalanes. Asimismo se reflexiona entorno a como se ha abordado teóricamente el asunto de las migraciones, identificando porqué no existen teorías generales para su estudio, y proponiendo algunas líneas de trabajo en este sentido.

Se presentan a continuación cuatro hipótesis de las cuales dos constituyen las líneas principales de la investigación, quedando otras dos como consecuencias derivadas del proceso migratorio. La primera hipótesis hace referencia a la actual situación de la juventud catalana, caracterizada por el paro, la precariedad y la temporalidad laboral, con alto grado de cualificación, así como con pocas oportunidades para la emancipación. Se parte de que la situación actual no es fruto de la crisis, sino que se trata de condiciones permanentes en los jóvenes desde la restauración de la monarquía constitucional en 1978, lo que será demostrado a partir de un repaso a la legislación laboral en materia juvenil.

La segunda hipótesis, y línea principal de investigación, afirma que la causa principal de la emigración juvenil es la emancipación negada. Se debe entender emancipación como la posibilidad de poseer un proyecto propio de vida en el tránsito hacia la edad adulta, para lo que se necesita una educación universal, un trabajo estable y un acceso garantizado a la vivienda. Una emancipación negada por un sistema productivo que ha expulsado a la mayoría de los jóvenes y que es incapaz de reabsorber en otros sectores, dejando a la mayoría de la población juvenil en situación de desempleo o grave precariedad laboral. Una emancipación negada por un imposible acceso a una vivienda digna, a causa de un mercado caracterizado por una fuerte especulación que dejó a las rentas bajas -en la que se incluyen los jóvenes- sin casa o con hipotecas que no pueden ser liquidadas. Todo ello imposibilita la construcción de proyectos propios de vida, que es lo que en definitiva buscan los jóvenes en otros países principalmente europeos.

Otra de las hipótesis hace referencia ya a la situación de los jóvenes una vez realizado el movimiento al extranjero. Se sostiene que la situación económica y laboral no mejora sustancialmente en el extranjero, al acceder a empleos precarios y poco estables. Esta hipótesis será de difícil comprobación, ya que no existen datos de ningún tipo sobre la situación de los 
jóvenes en el extranjero, quedando únicamente el recurso de las entrevistas realizadas a jóvenes catalanes emigrados.

La cuarta, y última, de las hipótesis advierte de la posibilidad de la generalización del no retorno por parte de los jóvenes emigrados, hecho que tendría consecuencias graves en la estructura social de Cataluña, y el resto del Estado. Las expectativas de mejora en las ciudades de origen tardarán en llegar, lo que sumado a que los países del centro europeo pueden ofrecer algo más de estabilidad, y la condición de jóvenes que inician un nuevo proyecto de vida sin dejar prácticamente nada atrás en sus ciudades origen, refuerzan la idea de la hipótesis.

A lo largo de la investigación se utilizan diferentes metodologías. En primer lugar se realiza una revisión bibliográfica para el análisis teórico e histórico de la cuestión migratoria, así como de la historia de la legislación laboral en España a partir de manuales de Historia Económica.

La explotación estadística del Padrón continuo, las estadísticas de migración y los indicadores laborales de la EPA se utilizan para los apartados analíticos y descriptivos de la situación demográfica en Cataluña, así como de forma más concreta para el análisis de la situación de la juventud catalana.

Fuente de nueva información son los cuestionarios a 30 jóvenes de entre 18 y 30 años nacidos en Cataluña y que actualmente se encuentran residiendo en el extranjero ${ }^{11}$. El cuestionario realizado para el estudio consta de unas primeras preguntas de control, a partir de las cuales se clasifican a los encuestados, teniendo en cuenta cierto equilibrio entre las variables (sexo, edad, ciudad de origen, residencia actual, nivel de estudios y profesión actual). De estas primeras preguntas se extrae cierta información, pero se ha preferido utilizarlas como mecanismos de control para el perfil buscado en la investigación.

El cuestionario continúa con dos apartados más; el primero contiene preguntas en referencia a la situación del encuestado antes de emigrar, y la segunda contiene preguntas respecto a la situación posterior a la emigración. El tipo de pregunta, de carácter abierto, pretende dar opción al investigador para codificar las diferentes respuestas, así como al entrevistado de justificar cada una de ellas, aportando más información de carácter cualitativo a la investigación, fundamental para un caso de estudio con serias dificultades en su contabilidad.

\section{Cuestiones teóricas}

Se realiza en este apartado un repaso teórico de las diferentes contribuciones al estudio de las migraciones partiendo de la inexistencia de un corpus teórico que permita su análisis con un conjunto de principios, conceptos, y herramientas teóricas ampliamente aceptadas ${ }^{12}$. Asimismo la problemática en el presente artículo no pretende ser abordada desde un enfoque

\footnotetext{
${ }^{11}$ Puede consultarse en el Anexo que se encuentra al final de este mismo artículo

${ }^{12}$ ARANGO, J; “La explicación teórica de las migraciones: luz y sombra”, en Migración y Desarrollo №1 Octubre 2003
} 
estrictamente demográfico, sino que se analiza como una consecuencia que la crisis económica y política que se vive en España ha dejado sobre los sectores más jóvenes de la población.

Se centra la atención en la crítica a la teoría neoclásica y las posteriores versiones de la misma de Stark (1993) y Piore (1979). Asimismo se rescatan las concepciones generales que constituyen la Teoría del Sistema Mundial de Wallerstein junto a otras aportaciones, cómo las de Samir Anim (1985) o Arthur Lewis (1979). La elección de los autores se realiza de acuerdo a la importancia que han tenido en el estudio de las migraciones contemporáneas y siguiendo la clasificación que la geógrafa británica Doreen Massey realizara en $1993^{13}$.

Se sintetizan a continuación los enunciados que constituyen el marco teórico del trabajo, desprendidos fundamentalmente de la validez otorgada y las críticas realizadas a unas y otras aportaciones teóricas. En primer lugar, de las deficiencias ${ }^{14}$ de la teoría neoclásica (Todaro, 1976) se debe inferir que los estudios y análisis de fenómenos migratorios deben ser lo más transversales posibles, atendiendo a la realidad económica, política y social en la que se enmarcan. No se pueden atribuir las causas tan sólo a una de las esferas de la estructura social, ya que las sociedades no son economía o política, empleo o inversiones; son todo ello y mucho más, al contrario de la concepción de Michael Piore ${ }^{15}$. Asimismo se debe tener en cuenta que cada sistema productivo dará lugar, pues, a unos desplazamientos de población específicos.

Por otro lado se debe entender cualquier flujo migratorio como un proceso social, ya que entendido como flujo no puede deberse a la toma de decisiones de carácter individual, sino a movimientos poblacionales causados por diferentes motivaciones personales pero determinados por decisiones políticas que afectan a la estructura social. Las migraciones son eminentemente relaciones sociales, como lo son el trabajo o el salario, por ejemplo ${ }^{16}$. En tercer lugar, y teniendo en cuenta lo comentado anteriormente en el mismo párrafo, el marco teórico no puede sino considerar a las migraciones procesos forzados. Forzados por estructuras económicas, sistemas políticos inestables, condiciones económicas difíciles, entre otras muchas razones. Condición necesaria para el movimiento forzado será entender la fuerza de trabajo como mercancía -aunque esta concepción sea totalmente falaz como señaló Karl Polanyi en La

\footnotetext{
${ }^{13}$ Figura 3.1. pág 61 de BLANCO, C; "Las migraciones contemporáneas", 2000

${ }^{14}$ Las críticas que comúnmente se atribuyen a la Teoría Neoclásica afirman que de ser cierto lo que afirma se darían flujos migratorios de mayor envergadura, y no existirán tantas diferencias entre países de similares condiciones económicos -similares niveles de capital y trabajo-. Por otro lado se considera que la concepción entorno a la economía como desigual distribución de capital y trabajo deja de lado las estructura política que de muchas maneras influye sobre la economía y el mercado de trabajo. Así pues la visión estática de la realidad, y su miopía al dividir el mundo en dos variables como son el trabajo y el capital invalidan su aplicación -como paradigmas de la disciplina económica y sociológica- en el estudio de las migraciones. TODARO, M; "International migration in developing countries", en "Population and Economic Change in developing Countries" University of Chicago Press 1980

${ }^{15}$ Michael Piore en su Teoría de los Mercados Duales, defiende la idea de la demanda constante de mano de obra por parte de las economías industriales en las que se requiere, por tanto, de mano de obra foránea para su sustento, justificando así los movimientos de población. PIORE, M; "Birds of passage: migrant labor in industrial societies", Cambridge Univ. Press 1979

${ }^{16}$ pág 11 de CARDELÚS, J y PASCUAL, À; “Movimientos migratorios y organización social”, 1979
} 
Gran Transformación ${ }^{17}$ al definir el trabajo, el dinero y la naturaleza como mercancías ficticias al no ser estas creadas para ser vendidas (Polanyi, 1944), desposeyendo a los trabajadores de sus medios de producción, lo que facilitará su desarraigo y su desplazamiento; los asalariados se mueven allá donde puedan vender su fuerza de trabajo (Sassen, 1988).

Los movimientos forzados de población tienen dirección fijada, no son aleatorios, pues entre otras cosas no son actos individuales de decisión, sino que dentro de un sistema económico global, con economías interdependientes, los movimientos se establecen entre centros y periferias. Así, las migraciones resultan necesarias para la estabilidad del sistema dominante; centros y periferias que pueden darse a diferentes escalas, a nivel mundial ${ }^{18}$, a nivel europeo 0 regional y a nivel nacional (Wallerstein, 1979).

Por último es preciso señalar lo necesario de una revisión crítica del armazón teórico para el estudio de las migraciones. Las Ciencias Sociales en su conjunto han aportado numerosos conceptos y herramientas conceptuales que se han ido demostrando insuficientes para el estudio de los flujos migratorios; aún más cuando se asiste a un cambio de paradigma en la totalidad de las esferas que conforma las estructuras sociales de las sociedades contemporáneas. Las realidades políticas y económicas están cambiando en la mayor parte del mundo: transiciones políticas, procesos revolucionarios, neocolonialismo empresarial, potencias en declive, países emergentes, la sociedad en red de la información, la constante revolución tecnológica. Todo apunta a décadas de cambios bruscos que evidentemente afectaran a los movimientos de la población a escala planetaria.

El reto es, pues, adecuar las herramientas y los conceptos para el estudio de las migraciones contemporáneas, haciendo uso de las revisiones históricas de las migraciones, ya que aunque en época de cambio el sistema capitalista sigue dominando gran parte de las economías mundiales. Asimismo es necesario para su estudio construir y ofrecer nuevos elementos teóricos para abordar casos concretos como el de los asalariados -lo que viene ocupando la mayoría de aportaciones teóricas hasta el momento-, las mujeres o los jóvenes. La clase social es determinante en la condición o no de emigrante, así como la de mujer o joven dictamina el flujo y las condiciones en las que se da la emigración al partir de situaciones compartidas por grupos sociales de similares condiciones.

\footnotetext{
${ }^{17}$ POLANYI, K; “La Gran Transformación. Crítica del liberalismo económico”, La Piqueta 1989

${ }^{18}$ La Teoría del Sistema Mundo considera las migraciones producto de la dominación del centro sobre la periferia inscrito en el orden internacional de estructura de clases y conflicto social. Surgidas de los desequilibrios entre centro, periferia y semi-periferia las migraciones no atenúan las diferencias entre esferas sino que contribuyen a perpetuarlas. Se arroja pues sobre las migraciones una concepción negativa, que interesa a las clases dominantes dentro del "sistema mundo". WALLERSTEIN, I; "EI moderno sistema mundial. La agricultura capitalista y los orígenes de la economía-mundo europea en el siglo XV". Madrid. 1979 Siglo XXI
} 


\section{El contexto de las múltiples crisis}

El fenómeno migratorio al que se quiere dar explicación se circunscribe en una contexto económico, político y social muy determinado, caracterizado por una profunda crisis económica y una respuesta a la misma que está acabando por desmantelar los servicios públicos, así como desmoronando las expectativas de miles de jóvenes. El austericidio -el combate suicida del déficit público y las políticas de austeridad- que viene siguiendo a la bancarrota de los principales bancos estadounidenses y europeos va sumiendo cada vez más en la recesión y la crisis a las economías europeas. El 2013, el sexto año después del estallido de la crisis financiera, vuelve a ser un año de recortes, recesión y paro, en especial para los países del sur de Europa (Krugman, 2008); y es que el centro y la periferia vienen definiéndose con mayor nitidez en el viejo continente desde el año 2008.

La crisis de la deuda, transformada en "pública" a base de inyecciones de dinero público en los bancos rescatados, se ha erigido como la principal excusa para la aplicación de las políticas de austeridad que deben acabar con una de las conquistas más importantes de las fuerzas antifascistas de posguerra: el Estado social ${ }^{19}$. El déficit es desde hace unos años una obsesión a combatir que conduce a enormes recortes presupuestarios que deterioran nuestros ya débiles servicios públicos.

La situación es, pues, de cierta emergencia social en la Europa del sur, y lo acabará siendo en casi toda Europa, cuando la recesión económica -que afectó al motor alemán y a Franciaahonde. Esto junto a las imposibles exigencias del FMI obligarán a nuevos paquetes de recortes y ajustes, que acaben -¿quién sabe?- en otra oleada de rescates a estados miembros, con el España a la cabeza de todas las apuestas ${ }^{20}$.

La emergencia social se traduce en cifras y números, en los que se esconden dramas personales de distinta índole. Las cifras del paro para los países más afectados son de 27,2\% para Grecia, un $26,7 \%$ para España y un 17,5\% para Portugal, muy por encima de la media de la eurozona que se sitúa en el $12,1 \%$, todos datos de Marzo de $2013^{21}$.

En lo que se refiere a las cifras de la evolución del PIB, importante indicador para la recuperación del empleo sea de la calidad que sea, refleja una Eurozona sumida en la recesión y con pocas expectativas -al margen de las falsas ilusiones que arroja la Troika- de recuperación. Grecia, de nuevo, se sitúa a la cabeza con un $-6,3 \%$, le sigue Chipre con un $-4^{\prime} 9 \%$, Portugal e Italia con un -

\footnotetext{
${ }^{19}$ DOMENECH, A; “El Eclipse de la fraternidad: una revisión republicana de la tradición socialista”, Crítica 2004

${ }^{20}$ En el momento de la revisión de este artículo el contexto económico y político de la Unión Europea se encuentra marcado por la victoria de Syriza en las últimas elecciones griegas de Enero de 2015, y por la posibilidad de una auditoría y cancelación de parte de la deuda griega. Los rescates a los Estados Miembros han sido substituidos por ayuda más o menos periódica por parte del Fondo Europeo y la nueva política del BCE. ROBERTS, M; “EI BCE, QE y como escapar al estancamiento”, SinPermiso 25/1/2015

${ }^{21}$ Fuente: Eurostat, datos para Marzo de 2013
} 
$2,7 \%$ y un $-2,6 \%$ respectivamente, España con un -1,5\%, y una media para la Unión Europea del $0,6 \%{ }^{22}$.

Con tan sólo estos datos se puede dibujar un panorama poco esperanzador. A medida que los beneficios de la banca y las principales empresas españolas aumentan, la pobreza -también la infantil- se abre paso, con especial crudeza en España. Los servicios públicos -baluarte de la Europa de posguerra- se encuentran cada día más maltrechos y sin capacidad de garantizar sendos accesos universales. Debe sumársele las elevadas tasas de paro que están provocando una sangría constante de desempleados, que no pueden pagar las deudas que acumularon durante el período de bonanza, alentados eso sí por un consumismo que actuaba como carbón para la locomotora.

Pero la crisis económica mundial encuentra particularidades en el Estado español. En él coinciden crisis de diferente carácter pero que sin lugar a dudas todas llevan a una inevitable crisis de régimen. La crisis económica en España es fundamentalmente una crisis de modelo productivo. Los sectores estratégicos de la economía española han sido hasta ahora el de la construcción y el turismo. El primero ha sido un sector de elevada especulación que ha generado de un lado tasas de beneficios inimaginables al sector bancario y a un puñado de constructoras, y de otro, una expulsión enorme de trabajadores y un drama como el de los desahucios en España. Todo ello tomado en su conjunto constata la existencia de diferentes caras de una misma crisis.

El Régimen constituido en poder durante los años finales de la década de los setenta se concreta en la restauración de los Borbones en la monarquía y la Constitución de 1978. Este Régimen político del que se desprende el régimen económico y el sistema productivo se encuentra hoy amplia y socialmente cuestionado. La crisis de régimen se manifiesta en cuatro hechos principales $^{23}$, a los que en un futuro se podrían añadiendo más, como ha sido en la recta final de la actual legislatura el aumento y recrudecimiento de la represión a los movimientos sociales y la ciudadanía $^{24}$, que ha aumentado su capacidad de respuesta contestataria a partir del ciclo de movilizaciones iniciado el 15 de Mayo de 2011, prueba también de la crisis de legitimidad del Régimen de Transición ${ }^{25}$. La monarquía, pieza fundamental de la estabilidad política del Régimen constitucional del 78, se encuentra hoy con índices de popularidad bajos a raíz de diferentes escándalos y presuntos casos de corrupción en el seno de la familia real. Muestra de esta debilidad es sin duda la abdicación de Juan Carlos I y el rápido relevo y coronación de su hijo Felipe de Borbón ${ }^{26}$.

\footnotetext{
${ }^{22}$ Fuente: Eurostat, datos para el año 2012

${ }^{23}$ Domènech, A; "Sueltos (I): Sobre la crisis de la Segunda Restauración Borbónica y el llamado "conflicto territorial", SinPermiso 9 de Marzo de 2014

${ }^{24}$ Pisarello, G; "La Ley de Seguridad Ciudadana: hacerse temer, hacerse odiar", SinPermiso 14 de Diciembre de 2014

${ }^{25}$ Domènech, X; “Hegemonías. Crisis, movimientos de resistencia y procesos políticos (2010-2013)”, Akal Barcelona 2014

${ }^{26}$ Domènech, A, Buster, G, Raventós, D; “Una abdicación humillante para un golpe constitucional de perspectivas nada halagüeñas", SinPermiso 3 de Junio de 2014
} 
A estos escándalos se debe sumar los innumerables casos de corrupción que afectan a los principales partidos que han tenido poder en los 35 años de régimen constitucional ${ }^{27}$. Gürtel, Pretoria, Mercurio, ITV, Palau, son constantes las publicaciones de nuevas imputaciones de políticos presuntamente -o abiertamente- corruptos, convirtiéndose la corrupción en un mal endémico propio del sistema, y no tan sólo de casos aislados de un partido en concreto. Pero si hay corruptos es que existen corruptores, y estos son fundamentalmente las grandes empresas españolas que buscaron los favores de los diferentes gobiernos a cambio de grandes cantidades de donaciones a los respectivos partidos políticos. Hoy es todo esto una realidad política pública y reconocida.

El bipartidismo y la alternancia de poder entre conservadores y socialistas sobre los que descansa el sistema político español se encuentran ya en fase avanzada de descomposición ${ }^{28}$. La legitimidad de los principales partidos está seriamente dañada, por los casos de corrupción primero, y por las políticas contra la mayoría social que imponen sin ningún cargo de conciencia aparente en segundo lugar. La injusticia de los desahucios, los brutales recortes en sanidad y educación, la ruina de miles de pequeños empresarios, la sangría constante de desempleados, todo ello con el telón de fondo de sobresueldos y corrupción, han hecho saltar por los aires el bipartidismo, que según las encuestas hoy difícilmente superaría el $50 \%$ de los votos en unas elecciones legislativas.

El debate nacional es la última concreción de la crisis de régimen. El debate alrededor del derecho a decidir que en Cataluña es hoy una realidad cotidiana desafía el Estado de las Autonomías que configurara en su momento la Constitución del 78. Conflictos entre burguesías nacionales al margen, se abre paso un debate que acabará por reconfigurar las posiciones en cuanto al independentismo, el federalismo y el centralismo, dando lugar a un nuevo sistema político de estructura diferente al que hoy existe. Todas las cuestiones tratadas dibujan una necesaria ruptura con el Régimen actual salido de las cenizas de la dictadura franquista, que deja un sistema productivo en crisis y un sistema político socialmente cuestionado.

El paro, la precariedad y la temporalidad son características propias de los jóvenes en escenarios precrisis. No obstante la crisis de Régimen encuentra caracterización propia en los jóvenes. El paro juvenil que asciende hoy a más de la mitad de los jóvenes conduce a una expulsión total del mercado de trabajo de los que principalmente debería estar haciéndolo. El cada vez más restringido acceso a la educación superior y el ataque a la calidad educativa en niveles inferiores, ponen a los y las estudiantes -jóvenes en su mayoría- en condiciones de endeudamiento para pagar sus estudios, sin que ningún poder se avergüence ante las subidas de tasas o las restricciones en las becas.

\footnotetext{
${ }^{27}$ Domènech, A, Buster, G, Raventós, D; “El caso Bárcenas en el contexto de la crisis de la Segunda Restauración Borbónica", SinPermiso 4 de Febrero de 2013

${ }^{28}$ Domènech, A, Buster, G, Raventós, D; “El estado de un bipartidismo dinástico en descomposición”, SinPermiso 25 de Febrero de 2013
} 


\section{Situación de la juventud}

A continuación se analizan los datos más relevantes para realizar el diagnóstico de la actual situación de los jóvenes en Cataluña, que en el trabajo se considera elemento fundamental para la explicación de la emigración juvenil. La principal hipótesis del trabajo apunta a la situación de los jóvenes -a su emancipación negada- como motivación principal para la emigración.

El Gráfico 1 apunta a una dura realidad en lo que se refiere a las expectativas en el encuentro de un empleo, sin entrar a considerar las condiciones en las que trabajan aquellos que lo hacen. Como se ha podido observar en la representación gráfica del paro total de Cataluña y España, en este caso ocurre que ambas tasas siguen una tendencia similar, siendo la tasa de Cataluña más baja que la de España.

En el caso de la tasa de paro para los menores de 25 años partimos de una situación de tasas de paro superiores al 15\%, que han encontrado un fuerte incremento a partir del tercer trimestre de 2008 donde se superaba el $35 \%$ de paro juvenil. No es hasta 2010 cuando se supera ya el $40 \%$, hasta llegar a la actual tasa de paro del 57\% aproximadamente en el último trimestre de 2013, representando el máximo histórico en España.

En el Gráfico 3 se puede observar cómo de esa mitad de jóvenes que buscan empleo y lo encuentran más del $90 \%$ lo hacen con contratos temporales, la inmensa mayoría de ellos de obra y servicio, eventuales o de prácticas, lo que da buena cuenta de la precariedad y temporalidad laboral de la juventud en Cataluña.

Se abordan ahora las estadísticas referidas a los flujos de emigración con el extranjero de los jóvenes de nacionalidad española en Cataluña. La Tabla 1 indica que la emigración de jóvenes es una realidad al menos desde el año 2008 -inicio del registro de este tipo de datos-, que a lo largo de los últimos años ha ido creciendo, y creciendo cada vez más, hasta alcanzar la salida de más de 2000 jóvenes de 15 a 30 años de nacionalidad española de Cataluña en el año 2011.

Si se pone la atención sobre cada una de las franjas se observa como todas incrementan sus efectivos con el paso de los años. No obstante, la franja con más efectivos es la de 25 a 29 años que representan más del $50 \%$ de las salidas del total de los jóvenes con nacionalidad española. Esa franja de edad incluye los licenciados sin años de experiencia laboral, que probablemente la finalización de estudios y las nulas expectativas de encontrar un empleo estable les ha obligado a emigrar. En esta franja de edad el incremento se mantiene estable a lo largo del período analizado, aunque sí aumenta ligeramente en el año 2011. Por el contrario las dos franjas más jóvenes si presentan incrementos más fuertes de 2009 a 2010 y de 2010 a 2011. En las edades comprendidas entre 20 y 24 años encontramos a los jóvenes, en su mayoría estudiantes muchos de ellos universitarios que se acogen a programas de movilidad- así como también un grupo importante de recién titulados.

Por último en la franja comprendida entre los 15 y 19 años se encuentran los jóvenes que se han visto obligados a emigrar seguramente por el retorno de sus padres, inmigrados de los flujos de 
final del siglo XX, a sus países de origen. No obstante también encontramos jóvenes mayores de edad que han podido iniciar ya su emigración al exterior.

A continuación se presentan los datos que ofrece el Instituto de Estadística de Cataluña (IDESCAT) de los flujos de emigración al exterior durante el año 2011. A pesar de haberse representado ya en la tabla 1 IDESCAT muestra una realidad más precisa y más accesible, que permite realizar un análisis global de la emigración en Cataluña para el año 2011. Se constata de nuevo que más de 3.300 jóvenes de nacionalidad española salieron el año 2011 de Cataluña al extranjero, representando el 7,5\% de todas las emigraciones en la franja de edad de 16 a 34 años, siendo el resto emigraciones de extranjeros.

Si el cómputo se realiza entre todas las salidas de los nacionales por grupos de edad, se observa como el grupo de los jóvenes -de 16 a 34 años- representan el 36,27\% de las salidas de todos los nacionales al extranjero el año 2011. Así pues se constata de nuevo una nueva realidad que va incrementándose a medida que la crisis económica -y las políticas de respuesta a la misma- se acentúan; se debe tener en cuenta que los datos representados son para el año 2011, cuarto de una crisis que encara ya su séptimo año.

\section{La causa principal: la emancipación negada}

Con la radiografía de la situación de los jóvenes expuesta, habiendo presentado una aproximación al contexto europeo, y habiendo situado algunas de las líneas teóricas, es momento ya de mostrar y argumentar las tesis principales en lo que se refiere a las motivaciones explicativas de la emigración juvenil. El marco que se presenta parte de una causa principal para explicar la emigración juvenil, esto es, la imposibilidad de emancipación de los jóvenes así como la construcción de un proyecto propio de acuerdo a la consideración personal de la vida buena, siguiendo la conceptualización que se realiza a través de la libertad republicana ${ }^{29}$.

Se entiende por emancipación la capacidad de tener recursos materiales para no depender de nadie; concretándose por un lado en una independencia económica, y por otro en una independencia domiciliaria de los padres o tutores. Para ello es imprescindible el acceso a un empleo estable y digno, y la garantía del acceso a una vivienda, factor fundamental para la emancipación en todos los estudios realizados en torno a esta cuestión.

Así pues se conceptualiza aquí la emancipación negada como la dificultad en el acceso a una vivienda digna y a un empleo estable, a lo que se debe sumar en la caracterización del adjetivo "negada", también la educación de calidad. Se sostiene aquí que el Sistema político, identificado en el Régimen que se inicia con la restauración de la monarquía parlamentaria y en la Constitución de 1978, al incorporar en la misma un modelo productivo concreto, es hoy incapaz de garantizar tres de los derechos que en su texto se promulgan: educación, trabajo y vivienda,

\footnotetext{
${ }^{29}$ RAVENTÓS, D; “Las condiciones materiales de la libertad”, El Viejo Topo 2007
} 
en sus artículos 27,35 y 47 respectivamente. Se trata de una negación -o incapacitación en la garantía- de derechos para amplias capas de la sociedad española, que en el caso de los y las jóvenes se convierte en una incapacidad de emancipación.

En lo que se refiere al empleo, se parte de la idea que el paro, la precariedad y la temporalidad han sido características que han acompañado a los jóvenes también en momentos de expansión económica. Para ilustrar esto cabe destacar diferentes series históricas, en primer lugar, de la evolución del paro juvenil, y, en segundo lugar, de los tipos de contratos con los que se emplean a los jóvenes.

Para el primer caso, se puede señalar la tasa de paro juvenil -personas de 16 a 29 años- en Cataluña para 1996 cuando el paro era del 29,8\%, para 2001, 2005, 2007 y 2012, en la que situó en el $13 \%, 11,9 \%, 15,7 \%$ y $37,1 \%$ respectivamente ${ }^{30}$. Evidentemente las tasas se incrementan de manera espectacular si tomamos en consideración únicamente a las franjas más jóvenes hasta 25 años, los que podríamos considerar la masa más importante de recién titulados. Lo que podemos extraer de los datos que se ofrecen es que en ningún momento el paro juvenil desciende del $10 \%$, y aunque consideremos que una tasa de paro de alrededor del $15 \%$ es moderadamente baja, podemos concluir que incluso en tiempos de máximo crecimiento y expansión económica el paro no descendía de ese $15 \%$.

En segundo lugar, se destacan los datos para la contratación de los y las jóvenes catalanas según que los contratos sean temporales o indefinidos. Para el año 2001, los contratos temporales para los jóvenes representaban el 85\% respecto a los indefinidos, en 2005 ascendieron a 87\%, justo en el año de inicio de la crisis, 2008, se situaron en el 82\%, y por último en 2012 ascendieron hasta representar el $90 \%$ de los contratos ${ }^{31}$. Los datos demuestran de forma clara que los jóvenes además de tener tasas de paro elevadísimas a lo largo de la historia, encuentran serias dificultades para encontrar un empleo estable que les garantice cierta estabilidad laboral y económica.

Los datos que se presentan son obviamente resultado de una política laboral que ha tenido la temporalidad y la precariedad como objetivos permanentes, hasta llegar a constituirse como verdaderos criterios para la creación de empleo juvenil. Para ilustrar esto, que ha sucedido sin duda en el presente con las dos últimas reformas laborales (la de 2010 del Gobierno Zapatero y la de 2012 del Gobierno de Rajoy), ambas contestadas con sendas Huelgas Generales, se pondrán de relieve diferentes ejemplos de legislación laboral.

El 28 de Octubre de 1988 el Gobierno de Felipe González aprobaba, sin el acuerdo de los agentes sociales, el Plan de Empleo Juvenil con el objetivo de reducir la tasa de desempleo de los más jóvenes, por entonces muy elevada a pesar de haber salido años antes de diferentes ciclos de depresión económica. La propuesta se centraba en la creación de un nuevo contrato, llamado "contrato laboral de carácter especial" dirigido a los trabajadores jóvenes, cuyo salario se fijaba

\footnotetext{
${ }^{30}$ Fuente: IDESCAT

${ }^{31}$ Fuente: IDESCAT
} 
en el Mímino Interprofesional que para 1988 se situaba en 264,69 euros (44.044 pesetas), dando opción a las empresas de beneficiarse de una bonificación del $100 \%$ en la cuota de la Seguridad Social, además de fijar una duración para dicho contrato de un mínimo de 6 y un máximo de 18 meses. Hay que destacar la retirada del Plan tras la histórica Huelga General del 14 de Diciembre de 1988.

Tan sólo 6 años después, en 1994 y en la agonía del último gobierno de Felipe González, llegaría una nueva Reforma Laboral donde el empleo juvenil, y su combate a partir de la precarización del empleo y el aumento de la temporalidad, serían de nuevo contestados con otra Huelga. El contexto en 1994 era notablemente diferente al de 1988; en este caso tras 1992, el año de las Olimpiadas de Barcelona y la EXPO de Sevilla, España se encontraba en una situación de paro elevadísimo -la tasa rebasaba el $20 \%$, tan sólo superada por el actual contexto de crisis- y con unas exigencias provenientes de Europa para la entrada en el mercado común de Maastrich. Para combatir las elevadas tasas de paro el Gobierno presentó de nuevo una Reforma Laboral, entre cuyas medidas se proponía la institucionalización del contrato de formación que se ampliaba a los 25 años, ofreciendo en realidad no jóvenes para ser formados, sino mano de obra barata. A este contrato de formación se le añade el contrato en prácticas de similares condiciones, siendo la más importante que, en este caso, el salario no podía ser inferior al $60 \%$ del SMI. De nuevo la precariedad y la temporalidad vienen incluidas en la legislación laboral, especialmente en las medidas que pretenden combatir el desempleo juvenil.

En el repaso a diferentes casos de legislación laboral cabe destacar en último lugar la reforma laboral de Julio de 2001 que se aprobó bajo el segundo gobierno de José María Aznar. De la reforma cabe destacar la extensión de las modalidades de contratos temporales que tiene origen en la reforma de 1994, para jóvenes de 16 a 29 años, así como para mujeres empleadas en sectores donde se encuentren subrepresentadas y parados de más de 6 meses.

Realizada la breve descripción de los cambios que introducen tres reformas laborales diferentes en España podemos concluir por tanto que efectivamente la legislación en materia laboral para los jóvenes ha ido siempre guiada por medidas que incrementaban la temporalidad y la precariedad de los contratos para jóvenes. Además, cabe tener en cuenta que las reformas laborales que se han comentado se realizaron bajo gobiernos de diferente signo político aunque adscritos al mismo Régimen Político que aquí se sitúa en el centro de la negación de derechos- y en condiciones económicas muy distintas, de expansión y de crisis económica.

Respecto a la cuestión del empleo y como idea fuerte que debe dar explicación a la tesis que se defiende es importante señalar una de las razones que explican, en parte, la elevada tasa de desempleo juvenil. Anteriormente se ha relacionado el sistema político actual de España, concretado en la Constitución de 1978, con el sistema productivo incluido en la misma Carta Magna basada en la economía especulativa del sector inmobiliario -potenciada también legislativamente- y el sector turístico, que entre ambos se han oxigenado mutuamente a lo largo de las décadas. El sector inmobiliario al demandar una mano de obra poco cualificada actuó como efecto llamada para muchos jóvenes al ofrecer elevados salarios que permitían cierta 
emancipación. La crisis financiera que colapsó el sector expulsó en primer lugar a los trabajadores más jóvenes, que hoy se encuentran sin empleo y sin estudios. Así, pues, el actual sistema productivo no es capaz de absorber a más trabajadores y menos a jóvenes y a mujeres.

El segundo de los derechos que se ha conceptualizado como la emancipación negada se refiere al de la vivienda. Hay que situar realmente en su momento el problema real de la vivienda en el Estado español, que no se inicia ni mucho menos con la crisis de 2008. El modelo productivo que ha caracterizado la economía española en los últimos decenios, y que se ha venido definiendo con anterioridad, tiene como momento cumbre los años noventa cuando se origina la conocida como "burbuja inmobiliaria". La especulación ha resultado ser la variable explicativa de un incremento del precio del suelo que crecía al $30 \%$ en el primer decenio del presente siglo, entre otros factores. Estos incrementos, junto a los datos de paro y temporalidad de la gente joven a lo largo de los últimos veinte años han propiciado una negación total del derecho a la vivienda digna de los jóvenes en el Estado español.

Otros factores del mismo orden deben ser tenidos en cuenta para la explicación de este hecho. En la ley de arrendamientos urbanos de 1994, la "cultura de la propiedad" en detrimento del alquiler propia de los países de la Europa del sur, las insuficientes políticas públicas de ayuda al alquiler, entre otras razones, contribuyen a explicar que en primer lugar, la mayoría de jóvenes no encuentren la oportunidad para la emancipación, y en segundo lugar, a explicar también la actual situación de muchas familias en peligro de desahucio, ahogadas por un crédito que no son capaces de devolver.

Con los datos expuestos se puede concluir de ellos que en ningún caso la situación de paro, precariedad y dificultad en el acceso a la vivienda son propias de escenarios de crisis. Se ha podido comprobar que situaciones como las que vivimos hoy, acentuadas obviamente por la crisis, ya existían en la sociedad española durante los años ochenta y noventa, conclusión fundamental para explicar el cómo se ha llegado a la situación de hoy en día, que en ningún caso se debe a un ritmo de vida acelerado, sino a una legislación y una política económica ficticia de especulación.

Conocida que la situación de los jóvenes catalanes ha empeorado con el avance de las políticas de austeridad en España, y constatado que esas condiciones tampoco eran buenas antes de la crisis lo que permite contrastar la primera hipótesis, cabe ahora presentar algunos datos relevantes extraídos de las entrevistas realizadas a jóvenes catalanes emigrados al extranjero.

Una vez emigrados, ¿̇los jóvenes logran obtener aquello que se les niega en Cataluña? Los datos son claros: la práctica totalidad de los encuestados afirma que tanto su situación laboral como personal ha mejorado en el extranjero, y que no se arrepienten de haber tomado la decisión de emigrar, lo que refuta la segunda de las hipótesis de la investigación. No obstante es importante destacar que a través de las respuestas cualitativas muchos afirmar que aunque su situación mejore se parte de unas condiciones profundamente precarias.

Se desprende de la misma pregunta una consideración relevante para el estudio teórico de las migraciones. Tan sólo uno de los encuestados afirma arrepentirse de haber tomado la decisión 
de emigrar mientras que el resto no muestra arrepentimiento. Esto hecho podría hacer pensar que la emigración es finalmente una decisión individual y voluntaria, sin embargo la coincidencia de la totalidad de encuestados en admitir que desearían tener el empleo precario que ocupan y la vida que llevan en el extranjero en sus respectivas ciudades de origen apunta a todo lo contrario. La emigración ha sido forzada y se constata que las migraciones son procesos sociales y no decisiones individuales, al encontrar un índice de respuesta de los encuestados tan elevado en la misma dirección.

Lo mismo ocurre con el riesgo elevado de no retorno, que constituye la última de las hipótesis. No se dispone de información de ningún tipo para resolver la validez o no de la cuarta hipótesis. No obstante los datos que arroja la encuesta son claros en este sentido. La amplia mayoría de los jóvenes encuestados no tiene fecha de regreso a Cataluña, y aquellos que afirman tenerla aseguran que abandonaran una ciudad extranjera para vivir en otra, pero nunca volver a Cataluña entra en sus planes de futuro inmediato. Estas afirmaciones son de vital importancia para la definición de conclusiones.

En primer lugar el no retorno queda validado al estar la decisión del regreso estrechamente vinculada a las oportunidades de estudio y empleo. Si hemos concluido que la situación de los jóvenes mejora ligeramente en el extranjero, el retorno no se antoja un proceso fácil de darse. $Y$ en segundo lugar, tenida en cuenta la afirmación que volver a Cataluña no es una opción de futuro inmediato refuerza la idea de la expulsión, de la emigración forzada, y descarta la del movimiento voluntario de jóvenes.

En este artículo tan sólo se han apuntado algunas de las causas que explican la salida de los jóvenes catalanes al extranjero, salida que ha venido acentuándose en los últimos años. La emancipación negada es señalada como la principal causa explicativa de la motivación de la salida al extranjero; negado el empleo y la formación de calidad, así como el acceso a la vivienda, la emigración se presenta como una de las vías principales de escapatoria a una situación cada vez más complicada para los jóvenes catalanes.

Así pues se sostiene que la emigración juvenil sin duda es forzada por una falta de condiciones materiales que permitan la emancipación de las personas jóvenes en Cataluña y en España. Emancipación que se ha determinado la constituyen tres derechos fundamentales como son la educación de calidad, el empleo estable y la vivienda digna. Esas condiciones materiales son desde hace décadas negadas por un sistema político que es incapaz de ofrecer un modelo productivo en el cual emplear a la gente joven -y a otros tantos millones de adultos-. Un sistema productivo sumido en una grave crisis y un sistema político socialmente cuestionado que se erigen como principales negadores -e incapacitados- para ofrecer los derechos que dan acceso a las condiciones materiales oportunas para dicha emancipación.

Podría ser objeto de otras investigaciones el estudio de las consecuencias de este fenómeno, una vez analizadas sus causas y la verdadera magnitud de su alcance. Esto último sin duda es una cuestión relevante, ya que las dificultades en la contabilización de los jóvenes en el 
extranjero, así como la definición de sus condiciones de vida, constituyen hoy un vasto campo de trabajo que requiere de una exploración más profunda.

Sería oportuno también profundizar en el análisis basado en la división "centro-periferia" en el marco europeo, que se ha utilizado como elemento relevante en el marco teórico de esta investigación. Estudiar las condiciones de los jóvenes de la Europa del Sur -Portugal, Italia y Grecia, además de España-, y sus dinámicas migratorias ayudaría a esclarecer si realmente la Europa a dos velocidades existe y si lo que se inició en el Tratado de Maastrich -una relación desigual entre Norte y Sur basado en la desindustrialización de los segundos-, ha empezado a cristalizar con la crisis económica que arranca en 2007.

Pero si algo ha motivado la realización de este artículo, y del posterior trabajo, es la complicada tarea de romper aquellas concepciones que consideran que el actual flujo migratorio de jóvenes catalanes al extranjero es una anécdota periodística sin base estadística para su estudio; o las habituales consideraciones en torno a la emigración como un proceso habitual y propio de los jóvenes en busca de nuevas experiencias, algo que quedará refutado con algunas de las conclusiones expuestas en el trabajo. Se pretende así dejar constancia que el proceso de emigración de los jóvenes catalanes es un fenómeno política, social y económicamente significativo, idea central a lo largo de toda la investigación.

Así pues este trabajo trata de las actuales y las pasadas condiciones de vida de los jóvenes, pero sobre todo de las esperanzas frustradas para toda una generación de personas que, aún estando ampliamente preparadas, no encuentran garantías para su futuro más inmediato, y a quienes no se les garantiza los derechos básicos para poder llevar a cabo un proyecto de vida propio en sus ciudades de origen.

\section{Bibliografía}

ACOSTA, A [et al]; "Emigración, pobreza y desarrollo", Catarata 2004

ARANGO, J; "La explicación teórica de las migraciones: luz y sombra" en Migraciones y Desarrollo Número 1 2003

BLANCO, C; "Las migraciones contemporáneas", Alianza 2000

CARDELÚS, J y PASCUAL, À; “Movimientos migratorios y organización social”, Península 1979

CARRERAS, A; "Historia económica de la España contemporánea: 1789-2009", Crítica 2010

DEATON, Angus; "The great escape: Health, Wealth and the origins Inequality", Princeton University Press 2013 DOMENECH, A; “El Eclipse de la fraternidad: una revisión repubicana de la tradición socialista”, Crítica 2004 DOMENECH, A; "Sueltos (I): Sobre la crisis de la Segunda Restauración Borbónica y el llamado "conflicto territorial", SinPermiso 9 de Marzo de 2014

DOMENECH, A, RAVENTÓS, D, BÚSTER, G; “España entra en la espiral de la muerte” en SinPermiso 2012

DOMENECH, A, RAVENTÓS, D, BÚSTER, G; "El estado de un bipartidismo dinástico en descomposición", SinPermiso 25 de Febrero de 2013 
DOMENECH, A, RAVENTÓS, D, BÚSTER, G; "El caso Bárcenas en el contexto de la crisis de la Segunda Restauración Borbónica", SinPermiso 4 de Febrero de 2013

DOMENECH, A, RAVENTÓS, D, BÚSTER, G; "Una abdicación humillante para un golpe constitucional de perspectivas nada halagüeñas", SinPermiso 3 de Junio de 2014

DOMENECH, A, RAVENTÓS, D, BÚSTER, G, PISARELLO, G; "Reino de España: pasmo, marasmo y fin de época" en SinPermiso 2011

DOMENECH, X; “Hegemonías. Crisis, movimientos de resistencia y procesos políticos (2010-2013)", Akal Barcelona 2014

HUSSON, M; “La austeridad fiscal y la rentabilidad: el doble dilema europeo" en SinPermiso 2012

KRUGMAN, P; "El retorno de la economía de la depresión y la crisis actual" Editorial Crítica 2009

MAJORAL, R (coord), PALOMEQUE, F, FONT, J y SÁNCHEZ, D ; “Cataluña : un análisis territorial”, Ariel 2002

MASSEY, D; "Theories on internacional migration: a review an appraisal"; Population and Development review, 1993 (431-466)

MIRET, P, "Pasado y presente de las pautas de emancipación juvenil en España"; CCCB, Barcelona 1997

PIKETTY, T; “Le capital au XXlème siècle”, Le Seuil 2013

PIORE, M; "Birds of passage : migrant labor and industrial societies", Cambridge Univ. Press, 1979

PISARELLO, G; "La Ley de Seguridad Ciudadana: hacerse temer, hacerse odiar", SinPermiso 14 de Diciembre de 2014

PISARELLO, G; “Procesos Constituyentes. Caminos para la ruptura democrática”, Editorial Trotta 2014

POLANYI, K; “La Gran Transformación. Crítica del liberalismo económico”, La Piqueta 1989

PUJADES, I y SOLSONA, M; "La Población de España de 1900 a 1975 a nivel nacional y provincial”, 1989

RAVENTÓS, D; "Las condiciones materiales de la libertad", El Viejo Topo 2007

ROBERTS, M; “EI BCE, QE y como escapar al estancamiento”, SinPermiso 25/1/2015

RODRIGO, M; “Antonio López y López, 1817-1883: primer Marqués de Comillas: un empresario y sus empresas", Fundación Empresa Pública 1996

ROMERO VALIENTE, JM; Capítulo “5. Migraciones" en "Tendencias demográficas durante el siglo XX en España", INE 2003

SASSEN, S; "The Mobility of Labor and Capital. A Study in International Investment and Labor Flow", Cambridge University Press, 1988

SERRANO, Pedro, "La Vivienda como determinante de la emancipación juvenil"; CCCB, Barcelona 1997

STARK, O; "La Migración del trabajo", Centro de Publicaciones. Ministerio de Trabajo y Seguridad Social, cop. 1993

TODARO, M; "International migration in developing countries", en "Population and Economic Change in developing Countries" University of Chicago Press 1980

YAÑEZ GALLADO, C; "La Emigración española a América : siglos XIX y XX : dimensión y características cuantitativas" Archivo de Indianos 1994

WALLERSTEIN, I; “El moderno sistema mundial. La agricultura capitalista y los orígenes de la economía-mundo europea en el siglo XV". Madrid. 1979 Siglo XXI 


\section{ANEXOS}

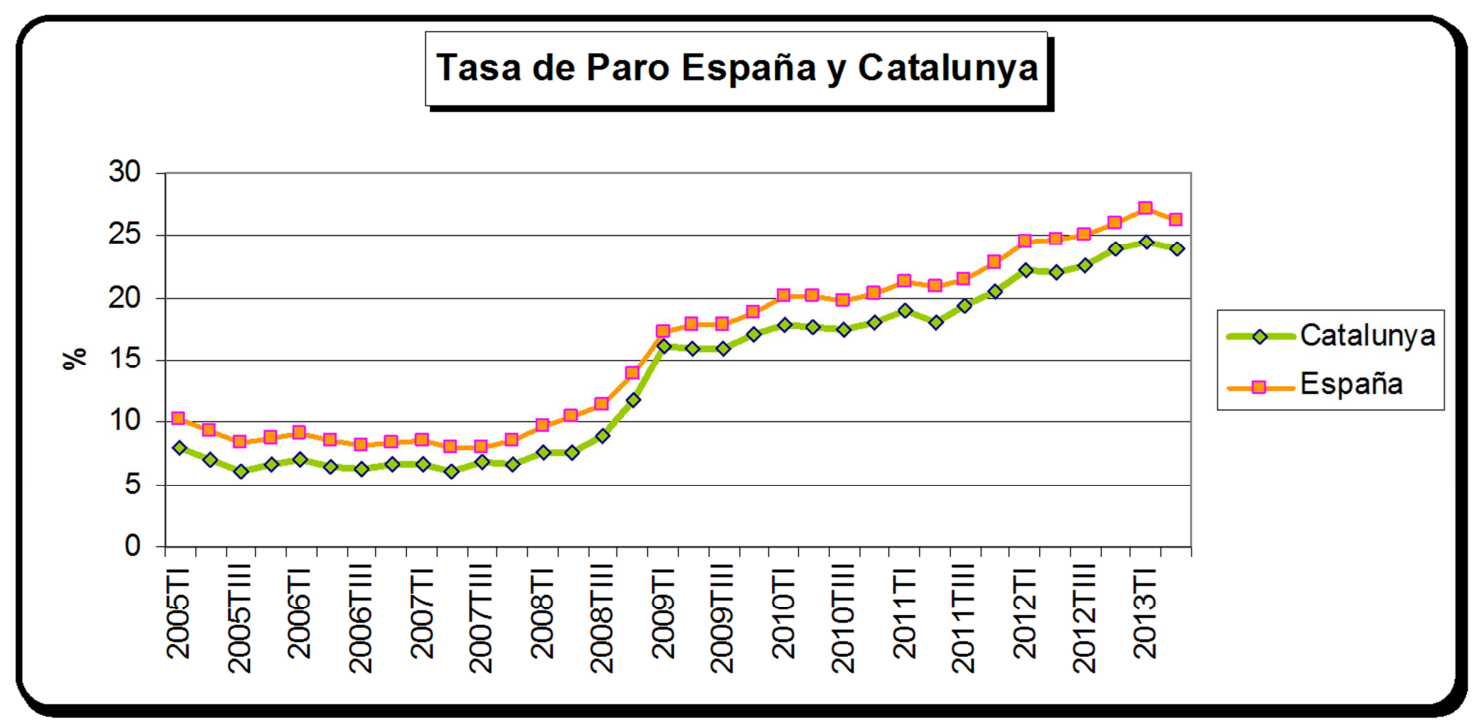

Gráfico1. Tasas de paro de España y Cataluña Elaboración propia. Fuente: INE

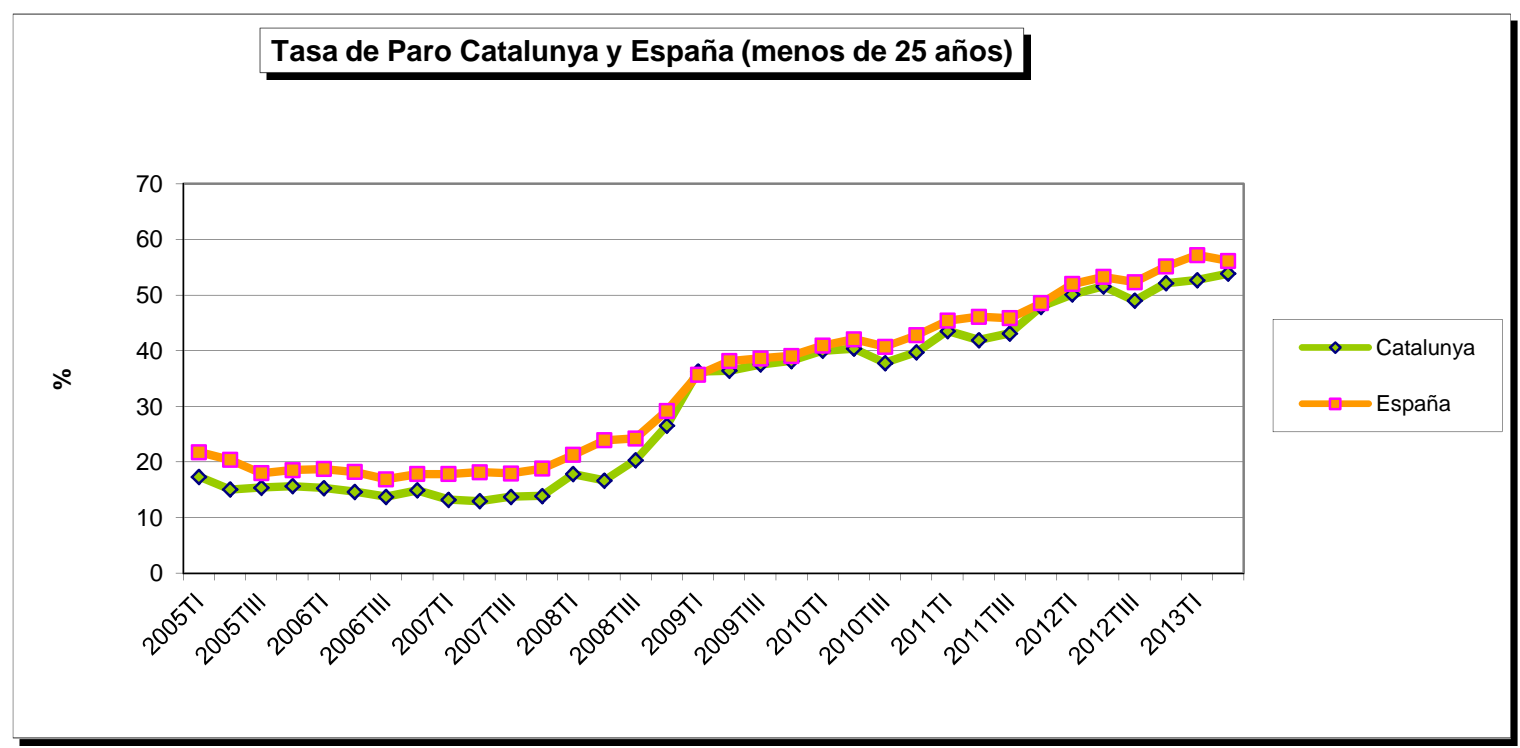

Gráfico2. Tasa de paro juvenil Cataluña y España

Elaboración propia. Fuente: INE 


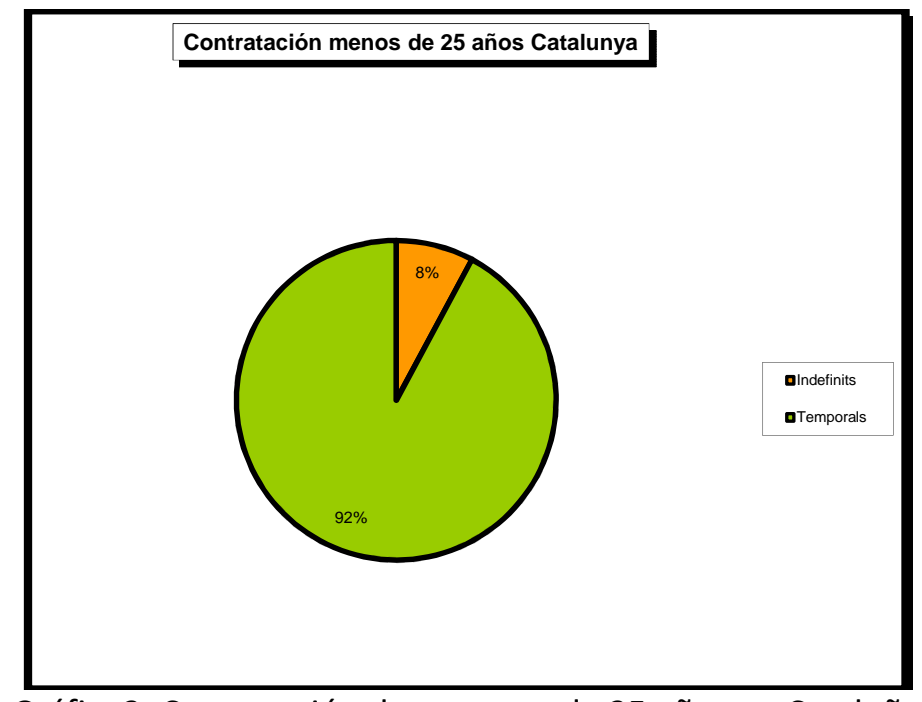

Gráfico3. Contratación de menores de 25 años en Cataluña Elaboración propia. Fuente: IDESCAT

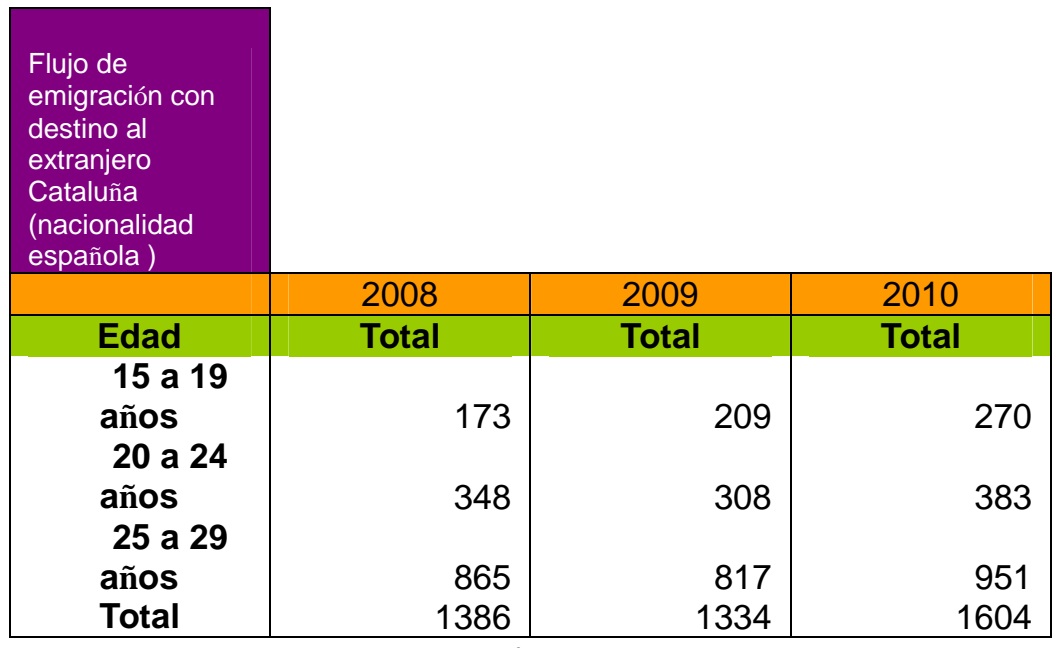

Tabla1. Flujo de emigración con destino al extranjero Elaboración propia. Fuente: INE 


\begin{tabular}{|c|c|c|c|c|}
\hline $\begin{array}{l}\text { Emigración } \\
\text { externa } \\
\text { según edad } \\
\text { Cataluña } \\
2011\end{array}$ & & & & \\
\hline Nacionalidad & $<16$ años & 16 a 34 & 35 a 54 & + de 55 \\
\hline Españoles & 1.994 & 3.334 & 2.951 & 914 \\
\hline Extranjeros & 10.364 & 43.932 & 30.167 & 6.933 \\
\hline Total & 12.358 & 47.266 & 33.118 & 7.847 \\
\hline Españoles (\%) & 21,69 & 36,27 & 32,1 & 9,94 \\
\hline Extranjeros (\%) & 11,34 & 48,07 & 33,01 & 7,59 \\
\hline Total (\%) & 12,29 & 46,99 & 32,92 & 7,8 \\
\hline
\end{tabular}

Tabla 2. Emigración externa según edad Cataluña 2011 Elaboración propia. Fuente: IDESCAT 


\section{Modelo de cuestionario confeccionado para el trabajo}

La entrevista que vas a realizar corresponde al trabajo de campo de una tesina del Máster Oficial de Planificación Territorial y Gestión Ambiental de la Universidad de Barcelona, cuyo objetivo es identificar los factores explicativos de la motivación de la emigración juvenil tanto a nivel estructural como individual. Esta entrevista forma parte del enfoque individual, de donde se pretenden construir los relatos a partir de vivencias concretas entorno a la emigración juvenil.

Las preguntas numeradas son de respuesta larga, alrededor de unas 5 líneas. No obstante utiliza el espacio que considere necesario. El anonimato de los y las participantes será debidamente preservado.

EDAD:

*VARIABLES SOCIO-DEMOGRÁFICAS:

SEXO:

CIUDAD DE ORIGEN:

RESIDENCIA ACTUAL (Ciudad y País):

NIVEL DE ESTUDIOS (Bachillerato, Título Universitario, Doctorado):

PROFESIÓN ACTUAL:

*DE LA SITUACIÓN ANTERIOR A LA EMIGRACIÓN:

1. ¿Cuál era tu situación laboral y/o profesional en tu ciudad de origen?

2. ¿Cuál era tu situación personal? ¿Qué elementos podían ligarte a tu ciudad de origen? (Por ejemplo: posesión de una hipoteca, tener pareja, la enfermedad de un familiar)

3. ¿Cuál es tu recorrido laboral y/o profesional hasta el momento de la emigración?

*DE LA SITUACIÓN POSTERIOR A LA EMIGRACIÓN:

4. ¿Cuáles han sido los motivos principales para la elección de tu actual ciudad de residencia? ¿Qué ofrecía? ¿Conocías alguien ahí? ¿Has encontrado alguien posteriormente?

5. ¿Podría identificar el momento, aquello que le determinó finalmente en su decisión de emigrar? (Por ejemplo: Un caso de despido, algún factor personal, la finalización de estudios, ruptura sentimental, disgusto personal)

6. ¿Cuánto tiempo llevas en la nueva ciudad de destino?

7. ¿Considera que su situación ha mejorado tras su traslado a otra ciudad? ¿Por qué? ¿Te arrepientes de la decisión de emigrar?

8. ¿Cuánto tiempo tienes pensado quedarte? ¿La decisión está ligada a la finalización de estudios, un contrato, etc...?

9. ¿Has entrado en contacto con otras personas de Catalunya o el resto del estado? ¿Se podría decir que existe una red de personas emigradas? ¿Qué otros contactos has realizado tras el traslado?

10. Por último, ¿cuál es tu valoración sobre el fenómeno de la emigración que actualmente afecta a la sociedad catalana y española? 